\title{
The k-Language Classification, a Proposed New Theory for Image Classification and Clustering at Pixel Level
}

\author{
Aslan Alwi ${ }^{1}$, Retantyo Wardoyo, M.Sc, Ph.D ${ }^{2}$, Agus Harjoko, M.Sc, Ph.D ${ }^{3}$, Munirah Muslim,S.Kom., MT ${ }^{4}$ \\ ${ }^{1}$ Student at Doctoral Program, Computer Science, Gadjah Mada University, Yogyakarta, Indonesia \\ ${ }^{2}$ Lecturer at Computer Science Departement, Gadjah Mada University, Yogyakarta, Indonesia \\ ${ }^{3}$ Lecturer at Computer Science Departement, Gadjah Mada University, Yogyakarta, Indonesia \\ ${ }^{4}$ Student at Doctoral Program, Computer Science, Gadjah Mada University, Yogyakarta, Indonesia
}

\begin{abstract}
This theory attempted to explore the possibility of using regular language further in image analysis, departing from the use of string to represent the region in the image. But we are not trying to show an alternative idea about how to generate a string region, where there are many different ways how the image or region produces strings representing, in this paper we propose a way how to generate regular language or group of languages which performs both classify the set of strings generated by a group of a number of image regions. Researchers began by showing a proof that there is always a regular language that accepts a set of strings that produced the image, and then use the language to perform the classification. Research then expanded to the pixel level, on whether the regular language can be used for clustering pixels in the image, the researchers propose a systematic solution of this question. As a tool used to explore regular language is deterministic finite automata. On the end part before conclusion of this paper, we add revision version of this theory. There is another point of view to revision version, added for make this method more precision and more powerfull from before.

Keywords; pixel, region, image, regular language, deterministic finite automata
\end{abstract}

\section{Introduction}

This paper is essentially all of the ideas that emerged in the course of digital image processing is followed by researchers, inspired by the contents of the lecture very interesting for researchers so that so many questions that researchers ask in it and enlightenment as well as the inspiration to write it in the results of intellectual contemplation a concept, if not too much, researchers are trying to formulate a theory that tried to summarize the results of such reflection. Researchers apologize if none use arguments (a theorem or standard definition) derived from previous research papers or textbooks before, all definitions, theorems and consequences expressed in this paper are solely the proposal of the theory that describes the research foundation researchers are trying to put forward independently. Therefore there are no citations used in this paper except the bibliography used solely as a research literature course.

By the way, because it is not directly based on the arguments of others explicitly, researchers tried to be guided by the logic of the system (the calculus of proposition and predicate calculus) and mathematical sets to validate any deductive statements expressed independently. May thus be a pretty solid foundation for the theory proposed.

We call this theory as a k-language, as a form of naming is commensurate with $\mathrm{k}$-mean. both have a very different perspective, the k-mean using a set of numbers in the way it works, the k-language using a set of string. But even so they are supervised classification.

This theory proposed subsequent decline can begin as follows:

Discussion of this idea about using regular language to perform up to the level of pixels clustering performed using deterministic finite state automata (DFA), in which a regular language has an equivalent representation with a DFA so simply by using the DFA, all the analysis and construction of regular languages can be done.

On Digital Image Processing lecture, noted that the region basically be represented by a string, so on an image of $n$-region can be obtained $n$ strings. Region inside the classification process is done by defining a distance metric that measures the similarity between strings. For whether it is a set of $n$ strings that may be forming a certain language that may be based on the language that one can perform analysis and classification

In the first part of this paper argued that there is always a regular language that accepts an arbitrary finite 
set of strings, then it can be constructed based on a language or some regular languages that can be used to analyze an image linguistically and also perform classification.

\section{Construction of regular language from a digital image}

In successive paragraphs below, researchers first proposed a theorem that states that if we have an arbitrary finite set of string then there will always be at least one regular language can be built and use the string set, which in its DFA representation means there is a minimal DFA automata who received the entire string. This proposal is the following theorem:

\section{Theorem 1 (Existence of Regular Languages):}

Suppose there is a finite set of arbitrary G string where the entire alphabet is from the set of alphabet E, then at least there is a regular language $\mathrm{L}$ which can be constructed for the entire string in the set $\mathrm{G}$.

Proof:

Because for any regular language $\mathrm{L}$ with a finite string can always be made an equivalent DFA, then take $\mathrm{M}=\{\mathrm{S}, \mathrm{E}, \mathrm{d}, \mathrm{s} 0, \mathrm{~F}\}$ as automata equivalence of regular languages $\mathrm{L}$.

where :

$\mathrm{S}=$ the entire set of states

$\mathrm{E}=$ any alphabet set of $\mathrm{L}$

$\mathrm{d}=\mathrm{a}$ mapping is defined as follows $\mathrm{d}: \mathrm{E} \times \mathrm{S} \rightarrow \mathrm{S}$

$\mathrm{s} 0=$ initial state

$\mathrm{F}=$ the entire set of final states

Then choose $\mathrm{F}=\mathrm{S}$, Then the automaton $\mathrm{M}$ accepts any string of any combination of the alphabet in E.

Suppose there is a string of any combination of alphabet $\mathrm{Y}$ in $\mathrm{E}$, ie $\mathrm{Y} \in \mathrm{E}^{*}$, and is not accepted by $\mathrm{M}$, then $\mathrm{Y}$ will end or finish in certain state e.g. A where $\mathrm{A}$ is not a member of $F$, i.e. $A \notin F$.

But A definite elements $\mathrm{S}, \mathrm{A} \in \mathrm{S}$, because $\mathrm{S}$ is a universal set of states, this means that $\mathrm{S}$ is not equal to $\mathrm{F}$, ie $\mathrm{S} \neq \mathrm{F}$.

This conclusion contradicts our choice for $F$, i.e $F=S$. Thus the evidence presented.

Based on the theorem that the researchers propose urther research proposes the following consequences:

\section{Result 1:}

Suppose that an image with $\mathrm{n}$ region in it, then the whole region was represented by a string respectively, then the image can be constructed in a certain regular language that accepts the set of strings formed by the entire region.

Proof: By theorem 1 is trivial.

\section{Result 2:}

Suppose that an image with $\mathrm{n}$ pixels making up, and each pixel can be represented by a string, then the image can be constructed in a certain regular language that accepts all strings generated by the pixels in the image.

Proof: By theorem 1 is trivial.
Thus these effects are proposed. As for how a pixel to produce a string, this being a separate ideas to be put forward at the end of the research paper, so it is hoped regular language can be used to perform clustering point on the image.

Further noted was about ideas on how to order the regular language $L$ that has ensured its existence there by theorem 1 can be used to perform classification.

\section{Regular language decomposition for classification}

For the purposes of this classification, the researchers first put forward an idea of the decomposition of regular languages. This idea is written exactly in the proposed definition as follows:

Definition 1 (Decomposition language):

Suppose a regular language $\mathrm{L}$ is equivalent to automata $\mathrm{M}=\{\mathrm{S}, \mathrm{E}, \mathrm{d}, \mathrm{s} 0, \mathrm{~F}\}$, written $\mathrm{L} \equiv \mathrm{M}$, then the decomposition of $\mathrm{L}$ written $\mathrm{L}=\mathrm{L}_{1} \oplus \mathrm{L}_{2} \oplus \mathrm{L}_{3} \oplus \ldots \oplus \mathrm{L}_{\mathrm{n}}$. where $\mathrm{L}_{\mathrm{i}} \equiv \mathrm{M}_{\mathrm{i}}, \mathrm{M}_{\mathrm{i}}=\left\{\mathrm{S}, \mathrm{E}, \mathrm{d}, \mathrm{s} 0, \mathrm{~F}_{\mathrm{i}}\right\}$ and $\mathrm{F}_{\mathrm{i}} \cap \mathrm{F}_{\mathrm{j}}=\varnothing, \mathrm{i}, \mathrm{j}=$ $1,2,3, \ldots$, n. i $\neq$ j.

By definition 1, the researchers suggest this may further stated the opinion that, an image which $\mathrm{k}$ region can basically be classified into the decomposition of regular languages $\mathrm{L}$ which by Theorem 1 is exist and can be constructed thereon.

Example:

Suppose that an image $\mathrm{G}$ with 3 region in it, each can be represented in the following strings:

Region $1=$ aaabb

Region $2=c c a b$

Region3 = cacabb

Create an automaton $\mathrm{M}=\{\mathrm{S}, \mathrm{E}, \mathrm{d}, \mathrm{s} 0, \mathrm{~F}\}$ where:

$\mathrm{S}=\{\mathrm{A}, \mathrm{B}, \mathrm{C}\}, \mathrm{E}=\{\mathrm{a}, \mathrm{b}, \mathrm{c}\}, \mathrm{s} 0=\mathrm{A}$, and selected $\mathrm{F}=\mathrm{S}$, and $\mathrm{d}$ can be chosen as follows:

Table 1. d state function selected

\begin{tabular}{|c|c|c|c|c|}
\hline \multicolumn{2}{|c|}{$\mathrm{d}$} & \multicolumn{3}{|c|}{ Input character } \\
\cline { 2 - 5 } & $\mathrm{A}$ & $\mathrm{A}$ & $\mathrm{b}$ & $\mathrm{c}$ \\
\hline \multirow{3}{*}{$\underset{\varpi}{*}$} & $\mathrm{~B}$ & $\mathrm{~B}$ & $\mathrm{~B}$ & $\mathrm{C}$ \\
\cline { 2 - 5 } & $\mathrm{C}$ & $\mathrm{C}$ & $\mathrm{B}$ & $\mathrm{A}$ \\
\cline { 2 - 5 } & & & $\mathrm{A}$ \\
\hline
\end{tabular}

Furthermore, based on definition 1, the decomposition of L generate $\mathrm{L}=\mathrm{L}_{1} \oplus \mathrm{L}_{2} \oplus \mathrm{L}_{3}$, where $\mathrm{L}_{\mathrm{i}}=\mathrm{M}_{\mathrm{i}}, \mathrm{M}_{\mathrm{i}}=\{\mathrm{S}, \mathrm{E}$, $\left.\mathrm{d}, \mathrm{s} 0, \mathrm{~F}_{\mathrm{i}}\right\}$ and $\mathrm{F}_{1}=\{\mathrm{A}\}, \mathrm{F}_{2}=\{\mathrm{B}\}, \mathrm{F}_{3}=\{\mathrm{C}\}$.

Retrieved $F_{i} \cap F_{j}=\varnothing, i, j=1,2,3$.

Region classification in the image of $\mathrm{G}$ is based on the decomposition of $\mathrm{L}$ is obtained:

Region2 or ccab $\in \mathrm{L}_{2}$

Region1, Region3 or cacabb, aaabb $\in \mathrm{L}_{3}$

Similarly, regions classification process of the image is based on the idea of decomposition is proposed language researchers.

Next on the following ideas, on how to perform image classification at a global level, which if given $\mathrm{n}$ image, how do image classification based on regular languages 
that can be constructed on each image?

The first researchers to propose a terminology, the concept of the dominant language. A language is dominant on an image if and only if he receives more regions in the image. This terminology researchers propose in the form of the following definition:

Definition 2 (Dominant Language):

Suppose $\mathrm{L}$ is a regular language that is constructed over an image of $\mathrm{G}$, where $\mathrm{L}$ can be decomposed into $\mathrm{L}=$ $\mathrm{L}_{1} \oplus \mathrm{L}_{2} \oplus \mathrm{L}_{3} \oplus \ldots \oplus \mathrm{L}_{\mathrm{n}}$, if the classification of all the regions in the image of $\mathrm{G}$ causes card $\left(\mathrm{L}_{\mathrm{i}}\right)=\max \left(\operatorname{card}\left(\mathrm{L}_{1}\right)\right.$, card $\left(\mathrm{L}_{2}\right)$, card $\left(\mathrm{L}_{3}\right), \ldots$, card $\left.\left(\mathrm{L}_{\mathrm{n}}\right)\right), \mathrm{i}=1,2,3, \ldots, \mathrm{n}$ then $\mathrm{L}_{\mathrm{i}}$ expressed as the dominant language in the image of $\mathrm{G}$.

Furthermore, researchers argue that two images said to a group if only if both have the same dominant language. This way is the first to build a language L by Theorem 1 that receives the entire region in the whole image. This group proposed the idea in the form of the following definition:

Definition 3 (the way for classification):

Given the number of images, which can be built a language $\mathrm{L}$ is accepted throughout the region on the whole image. Two images in a language said to a group (have the same common language) if and only if they have the same dominant language.

Examples of the use of this idea:

Suppose there are images $\mathrm{G}_{1}, \mathrm{G}_{2}, \mathrm{G}_{3}, \ldots, \mathrm{G}_{\mathrm{n}}$, and created a language $\mathrm{L}$ is accepted throughout the region on the whole image of $\mathrm{G}_{1}, \mathrm{G}_{2}, \mathrm{G}_{3}, \ldots, \mathrm{G}_{\mathrm{n}}$, corresponding theorem 1, for example from decomposition and selection to every region throughout the images $G_{1}, G_{2}, G_{3}, \ldots, G_{n}$, found that the dominant language of $G_{3}, G_{5}$ is $L_{5}$ the same as the language of the dominant of $\mathrm{G}_{7}$, the classification results obtained $\mathrm{G}_{3}, \mathrm{G}_{5}, \mathrm{G}_{7} \in \mathrm{L}_{5}$.

Thus the idea was proposed as a new way to classify the image globally.

Later in the following chapter the researcher did propose a way on how to do clustering at the level of pixels in an image.

\section{Proposed ideas on how to do clustering at pixel level}

Using of regular language at the level of pixels of the image leads to a new question, namely how to represent how a pixel with a string?

At below researchers propose an idea on how to represent a pixel with a string, or how a pixel to produce a string.

The first time will be seen that $0,1,2,3,4,5,6,7,8,9$ is an alphabet, and therefore does not have the meaning of arithmetic and ordinal value.

The second will be seen that the mapping function that maps a pixel value for a pixel quantization values or grayscale value of $0-255$ is a string function. i.e. a function that maps a string of pixels with a combination of alphabet $\{0,1,2,3,4,5,6,7,8,9\}$. So it is no longer seen as a function of numbers (arithmetic). This idea was proposed in the form of the following definition:

\section{Definition 4 (string function of pixels):}

Let $\mathrm{E}=\{0,1,2,3,4,5,6,7,8,9\}$ is an alphabet and combinations thereof are seen as a string (not a number), and an image of $G$ is also set pixels then a mapping f that maps are one to one from a pixel to a combination of the alphabet, is written:

$f: G \rightarrow E^{*}$, called a pixel string functions.

Thus it can be seen that the fundamental has a pixel can produce or represented by a string.

Until this proposal, other researchers offer another way to represent a pixel with a string. This proposal is based on the nature neighborhoods of each pixel in the image.

The proposal put forward is exactly the definition 4.a as follows:

\section{Definition 4.a}

Suppose $A_{i}$ is an interval of integers in the interval $[0,255], i=1,2,3, \ldots, n$ where $A_{i} \neq \varnothing$ and $A_{i} \cap A_{j}=\varnothing$ for $\mathrm{i} \neq \mathrm{j}$ and an alphabet $\mathrm{E}=\left\{\mathrm{a}_{1}, \mathrm{a}_{2}, \mathrm{a}_{3}, \ldots, \mathrm{a}_{\mathrm{n}}\right\}$, the value of the alphabet $A_{i}$ is expressed by the following function:

\section{f: $A_{i} \rightarrow a_{i}$}

\section{Definition 4.b}

Suppose $g$ is a pixel in the image of $G$, and $A_{i}$ is an interval of integers in the interval $[0,255], i, j=1,2,3, \ldots$, $n$ where $A_{i} \neq \varnothing$ and $A_{i} \cap A_{j}=\varnothing$ for $i \neq j$ where value of $\mathrm{g} \in \mathrm{A}_{\mathrm{i}}$ and an alphabet $\mathrm{E}=\left\{\mathrm{a}_{1}, \mathrm{a}_{2}, \mathrm{a}_{3}, \ldots, \mathrm{a}_{\mathrm{n}}\right.$ and there is $\mathrm{a}$ mapping $f: A_{i} \rightarrow a_{i}$, then the pixel value $g$ alphabet is expressed by $\mathrm{a}_{\mathrm{i}}$.

Furthermore, based on the definition 4.a and 4.b can be argued that the idea of the neighboring string functions declared in the definition 5 .

\section{Definisi 5 (neighboring string functions):}

Suppose $\mathrm{g}$ is a pixel in the image of $\mathrm{G}$, and $\mathrm{Np}$ is the neighborhoods $\mathrm{p}$ on $\mathrm{g}$ and $\mathrm{A}_{\mathrm{i}}$ are intervals in $[0,255 \mathrm{i}=$ $1,2,3, \ldots, n$ where $A_{i} \neq \varnothing$ and $A_{i} \cap A_{j}=\varnothing$ for $i \neq j$ and an alphabet $\mathrm{E}=\left\{\mathrm{a}_{1}, \mathrm{a}_{2}, \mathrm{a}_{3}, \ldots, \mathrm{a}_{\mathrm{n}}\right\}$ then $\mathrm{g}$ string value based on $\mathrm{Np}$ expressed by mapping $\mathrm{f}_{\mathrm{Np}}$ :

$f_{\mathrm{Np}}: \mathrm{g} \rightarrow \mathrm{b}_{1} \mathrm{~b}_{2} \mathrm{~b}_{3} \ldots \mathrm{b}_{\mathrm{p}} \mathrm{b}_{\mathrm{p}+1}$

where $b_{i} \in E$ is the alphabet value of neighboring pixels to $i, p_{i} \in \mathrm{Np} i=1,2,3, \ldots \mathrm{p}$, and $b_{p+1}$ is the value of alphabet $\mathrm{g}$, whereas the value of the alphabet starts at left corner pixel over to the right, and apply:

$f: A_{i} \rightarrow a_{i}, E=\left\{a_{1}, a_{2}, a_{3}, \ldots, a_{n}\right\}$

Example:

Suppose $\mathrm{g}$ is a pixels in the image $\mathrm{G}$ and is have value 27 in grayscale. Create a grayscale intervals as follows: [0.5], [6.10], [11.15], [16.20], [21.25], [26.30], [31.35], [36.40], [41, 45], [46,50] and [51.255].

Create alphabet $E=\{a, b, c, d, e, g, h, i, j, k\}$ and alphabet function so that:
$\mathrm{f}[0,5]=\mathrm{a}$
$\mathrm{F}[6,10]=\mathrm{b}$
$\mathrm{f}[11,15]=\mathrm{c}$
$\mathrm{f}[21,25]=\mathrm{d}$
$\mathrm{f}[26.30]=\mathrm{e}$
$\mathrm{f}[31,35]=\mathrm{g}$
$\mathrm{f}[36.40]=\mathrm{h}$
$\mathrm{f}[41.45]=\mathrm{i}$
$\mathrm{f}[46,50]=\mathrm{j}$
$\mathrm{f}[51.255]=\mathrm{k}$

$\mathrm{g}$ pixel together are expressed in string: 


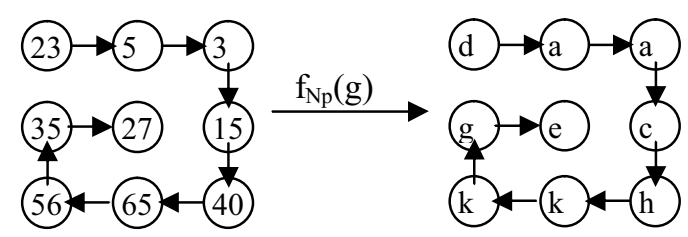

Illustration 1. Mapping $g$ by $\mathrm{f}_{\mathrm{Np}}$ So that the string of $g$ pixel obtained are as follows : $\mathrm{f}_{\mathrm{Np}}(\mathrm{g})=$ daachkkgc

Thus this proposal can be used to perform clustering of pixels in an image that is in the following way:

\section{Examples of clustering in an image by using regular} language

Suppose given an image of $\mathrm{G}$, Theorem 1 can be constructed by a regular language that accepts all pixels in the image. Choose $\mathrm{L}$ where $\mathrm{L} \equiv \mathrm{M}$ has the following description:

$\mathrm{M}=\{\mathrm{S}, \mathrm{E}, \mathrm{d}, \mathrm{s} 0, \mathrm{~F}\}$ where $\mathrm{S}=\left\{\mathrm{A}_{1}, \mathrm{~A}_{2}, \mathrm{~A}_{3}, \ldots, \mathrm{A}_{10}\right\}$ the number of states can be selected at will and are not restricted as in the previous theorem 1, and $\mathrm{E}=$ $\{0,1,2,3,4,5,6,7,8,9\}, d$ is chosen so that $d: E x S \rightarrow S$, for example have been $\mathrm{d}$ as follows:

Table 2 The d state function selected.

\begin{tabular}{|c|c|c|c|c|c|c|c|c|c|c|c|}
\hline \multirow{2}{*}{\multicolumn{2}{|c|}{ D }} & \multicolumn{10}{|c|}{ character input } \\
\hline & & \multirow{2}{*}{$\begin{array}{c}\mathbf{0} \\
\mathrm{A}_{1} \\
\end{array}$} & \multicolumn{9}{|c|}{2} \\
\hline \multirow{10}{*}{$\stackrel{\vec{\pi}}{5}$} & $A_{1}$ & & $\begin{array}{c}\mathbf{1} \\
\mathrm{A}_{2} \\
\end{array}$ & $\begin{array}{c}\mathbf{2} \\
\mathrm{A}_{3} \\
\end{array}$ & $\begin{array}{c}\mathbf{3} \\
\mathrm{A}_{4} \\
\end{array}$ & $\begin{array}{c}4 \\
A_{5} \\
\end{array}$ & $\begin{array}{c}5 \\
A_{6} \\
\end{array}$ & $\begin{array}{c}\mathbf{6} \\
\mathrm{A}_{7} \\
\end{array}$ & $\begin{array}{c}7 \\
\mathrm{~A}_{8} \\
\end{array}$ & $\begin{array}{c}\mathbf{\delta} \\
\mathrm{A}_{9} \\
\end{array}$ & \\
\hline & $\mathbf{A}_{2}$ & $\mathrm{~A}_{2}$ & $\mathrm{~A}_{3}$ & $\mathrm{~A}_{4}$ & $\mathrm{~A}_{5}$ & $\mathrm{~A}_{6}$ & $\mathrm{~A}_{7}$ & $\mathrm{~A}_{8}$ & $\mathrm{~A}_{9}$ & $\mathrm{~A}_{10}$ & $A_{1}$ \\
\hline & $\mathbf{\mathbf { A } _ { 3 }}$ & $\mathrm{A}_{3}$ & $\mathrm{~A}_{4}$ & $\mathrm{~A}_{5}$ & $\mathrm{~A}_{6}$ & $\mathrm{~A}_{7}$ & $A_{8}$ & $\mathrm{~A}_{9}$ & $\mathrm{~A}_{10}$ & $A_{1}$ & $A_{2}$ \\
\hline & \multirow{2}{*}{$\begin{array}{l}\mathbf{A}_{\mathbf{4}} \\
\mathbf{A}_{\mathbf{5}} \\
\end{array}$} & $\mathrm{A}_{4}$ & $\mathrm{~A}_{5}$ & $\mathrm{~A}_{6}$ & $\mathrm{~A}_{7}$ & $\mathrm{~A}_{8}$ & $\mathrm{~A}_{9}$ & $\mathrm{~A}_{10}$ & $\mathrm{~A}_{1}$ & $A_{2}$ & 13 \\
\hline & & $\mathrm{A}_{5}$ & $\mathrm{~A}_{6}$ & $\mathrm{~A}_{7}$ & $\mathrm{~A}_{8}$ & $\mathrm{~A}_{9}$ & $\mathrm{~A}_{10}$ & $\mathrm{~A}_{1}$ & $\mathrm{~A}_{2}$ & $\mathrm{~A}_{3}$ & $\overline{\mathrm{A}_{4}}$ \\
\hline & \multirow{2}{*}{$\begin{array}{l}\mathbf{A}_{\mathbf{6}} \\
\mathbf{A}_{7}\end{array}$} & $\mathrm{~A}_{6}$ & $\mathrm{~A}_{7}$ & $\mathrm{~A}_{8}$ & $\mathrm{~A}_{9}$ & $\mathrm{~A}_{10}$ & $\mathrm{~A}_{1}$ & $\mathrm{~A}_{2}$ & $\mathrm{~A}_{3}$ & $\mathrm{~A}_{4}$ & $\mathrm{~A}_{5}$ \\
\hline & & $\mathrm{A}_{7}$ & $A_{8}$ & $\mathrm{~A}_{9}$ & $\mathrm{~A}_{10}$ & $\mathrm{~A}_{1}$ & $\mathrm{~A}_{2}$ & $\mathrm{~A}_{3}$ & $\mathrm{~A}_{4}$ & $\mathrm{~A}_{5}$ & $\mathrm{~A}_{6}$ \\
\hline & \begin{tabular}{|l|}
$\mathbf{A}_{\mathbf{8}}$ \\
\end{tabular} & $A_{8}$ & $\mathrm{~A}_{9}$ & $\mathrm{~A}_{10}$ & $\mathrm{~A}_{1}$ & $\mathrm{~A}_{2}$ & $\mathrm{~A}_{3}$ & $\mathrm{~A}_{4}$ & $\mathrm{~A}_{5}$ & $\mathrm{~A}_{6}$ & $A_{7}$ \\
\hline & \multirow{2}{*}{\begin{tabular}{|c|}
$\mathbf{A}_{9}$ \\
$\mathbf{A}_{10}$ \\
\end{tabular}} & $\mathrm{~A}_{9}$ & $A_{10}$ & $\mathrm{~A}_{1}$ & $\mathrm{~A}_{2}$ & $\mathrm{~A}_{3}$ & $\mathrm{~A}_{4}$ & $\mathrm{~A}_{5}$ & $\mathrm{~A}_{6}$ & $\mathrm{~A}_{7}$ & $A_{8}$ \\
\hline & & $A_{10}$ & $\mathrm{~A}_{1}$ & $\mathrm{~A}_{2}$ & $\mathrm{~A}_{3}$ & $\mathrm{~A}_{4}$ & $\mathrm{~A}_{5}$ & $\mathrm{~A}_{6}$ & $\mathrm{~A}_{7}$ & $\mathrm{~A}_{8}$ & $\mathrm{~A}_{9}$ \\
\hline
\end{tabular}

and selected $\mathrm{F}=\mathrm{S}$, and $\mathrm{s} 0=\mathrm{A}_{1}$.

Further decomposition can be done at will against the desired L origin meets the definition 1 of the decomposition, suppose the desired decomposition in 10 languages. Then all the pixels in the image can be clustered in 10 clusters. namely $\mathrm{L}=\mathrm{L}_{1} \oplus \mathrm{L}_{2} \oplus \mathrm{L}_{3} \oplus \ldots \oplus \mathrm{L}_{10}$, where $\mathrm{L}_{\mathrm{i}} \equiv \mathrm{M}_{\mathrm{i}}=\left\{\mathrm{S}, \mathrm{E}, \mathrm{d}, \mathrm{s} 0, \mathrm{~F}_{\mathrm{i}}\right\}$ and $F_{i}=\left\{A_{i}\right\}, i=1,2,3,4,5,6,7,8,9,10$.

Clustering in 10 clusters can then be performed on $G$ for each pixel in $\mathrm{G}$, based on the previous definitions, researchers found three ways that can be selected to perform clustering, these three ways are as follows:

1. Using the definition 4 of string functions defined on $\mathrm{G}$.

$$
\begin{aligned}
& \text { Suppose : } \\
& \mathrm{f}(\text { Pixel1 })=233 \\
& \mathrm{f}(\text { Pixel2 })=143 \\
& \mathrm{f}(\text { Pixel3 })=20 \\
& \mathrm{f}(\text { Pixel4 })=0
\end{aligned}
$$

by passing on automata $\mathrm{M}$, obtained clustering result as follows:

$\mathrm{f}\left(\right.$ Pixel1), $\mathrm{f}\left(\right.$ Pixel2) $\in \mathrm{L}_{9}$

$\mathrm{f}\left(\right.$ Pixel3) $\in \mathrm{L}_{3}$

$\mathrm{f}\left(\right.$ Pixel4) $\in \mathrm{L}_{1}$
2. Next is an example of using the definition 5 of the neighbors string functions defined above $G$ for each point $\mathrm{p} \in \mathrm{G}$.

$\mathrm{M}=\{\mathrm{S}, \mathrm{E}, \mathrm{d}, \mathrm{s} 0, \mathrm{~F}\}$ where $\mathrm{S}=\left\{\mathrm{A}_{1}, \mathrm{~A}_{2}, \mathrm{~A}_{3}, \ldots, \mathrm{A}_{10}\right\}$ the number of states can be selected at will and are not

\begin{tabular}{|c|c|c|c|c|c|c|c|c|c|c|c|}
\hline \multirow{2}{*}{\multicolumn{2}{|c|}{ d }} & \multicolumn{10}{|c|}{ character input } \\
\hline & & $\mathbf{a}$ & b & c & d & $\mathbf{e}$ & $\mathbf{g}$ & $\mathbf{h}$ & $\mathbf{i}$ & $\mathbf{j}$ & $\mathbf{k}$ \\
\hline \multirow{10}{*}{ 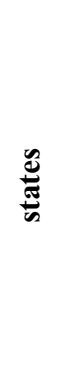 } & $\mathbf{A}_{1}$ & $\mathrm{~A}_{1}$ & $\mathrm{~A}_{2}$ & $\mathrm{~A}_{3}$ & $\mathrm{~A}_{4}$ & $\mathrm{~A}_{5}$ & $\mathrm{~A}_{6}$ & $\mathrm{~A}_{7}$ & $\mathrm{~A}_{8}$ & $\mathrm{~A}_{9}$ & $\mathrm{~A}_{10}$ \\
\hline & $\mathbf{A}_{2}$ & $\mathrm{~A}_{2}$ & $\mathrm{~A}_{3}$ & $\mathrm{~A}_{4}$ & $\mathrm{~A}_{5}$ & $\mathrm{~A}_{6}$ & $\mathrm{~A}_{7}$ & $\mathrm{~A}_{8}$ & $\mathrm{~A}_{9}$ & $\mathrm{~A}_{10}$ & $\mathrm{~A}_{1}$ \\
\hline & $\mathbf{A}_{3}$ & $\mathrm{~A}_{3}$ & $\mathrm{~A}_{4}$ & $\mathrm{~A}_{5}$ & $\mathrm{~A}_{6}$ & $\mathrm{~A}_{7}$ & $\mathrm{~A}_{8}$ & $\mathrm{~A}_{9}$ & $\mathrm{~A}_{10}$ & $\mathrm{~A}_{1}$ & $\mathrm{~A}_{2}$ \\
\hline & $\mathbf{A}_{4}$ & $\mathrm{~A}_{4}$ & $\mathrm{~A}_{5}$ & $\mathrm{~A}_{6}$ & $\mathrm{~A}_{7}$ & $\mathrm{~A}_{8}$ & $\mathrm{~A}_{9}$ & $\mathrm{~A}_{10}$ & $A_{1}$ & $\mathrm{~A}_{2}$ & $\mathrm{~A}_{3}$ \\
\hline & $\mathbf{A}_{5}$ & $\mathrm{~A}_{5}$ & $\mathrm{~A}_{6}$ & $\mathrm{~A}_{7}$ & $\mathrm{~A}_{8}$ & $\mathrm{~A}_{9}$ & $\mathrm{~A}_{10}$ & $\mathrm{~A}_{1}$ & $\mathrm{~A}_{2}$ & $\mathrm{~A}_{3}$ & $\mathrm{~A}_{4}$ \\
\hline & $\mathbf{A}_{6}$ & $\mathrm{~A}_{6}$ & $\mathrm{~A}_{7}$ & $\mathrm{~A}_{8}$ & $\mathrm{~A}_{9}$ & $\mathrm{~A}_{10}$ & $\mathrm{~A}_{1}$ & $\mathrm{~A}_{2}$ & $\mathrm{~A}_{3}$ & $\mathrm{~A}_{4}$ & $\mathrm{~A}_{5}$ \\
\hline & $\mathbf{A}_{7}$ & $\mathrm{~A}_{7}$ & $\mathrm{~A}_{8}$ & $\mathrm{~A}_{9}$ & $\mathrm{~A}_{10}$ & $\mathrm{~A}_{1}$ & $\mathrm{~A}_{2}$ & $\mathrm{~A}_{3}$ & $\mathrm{~A}_{4}$ & $\mathrm{~A}_{5}$ & $\mathrm{~A}_{6}$ \\
\hline & $\mathbf{A}_{8}$ & $\mathrm{~A}_{8}$ & $\mathrm{~A}_{9}$ & $\mathrm{~A}_{10}$ & $\mathrm{~A}_{1}$ & $\mathrm{~A}_{2}$ & $\mathrm{~A}_{3}$ & $\mathrm{~A}_{4}$ & $\mathrm{~A}_{5}$ & $\mathrm{~A}_{6}$ & $\mathrm{~A}_{7}$ \\
\hline & $\mathbf{A}_{9}$ & $\mathrm{~A}_{9}$ & $\mathrm{~A}_{10}$ & $\mathrm{~A}_{1}$ & $\mathrm{~A}_{2}$ & $\mathrm{~A}_{3}$ & $\mathrm{~A}_{4}$ & $\mathrm{~A}_{5}$ & $\mathrm{~A}_{6}$ & $\mathrm{~A}_{7}$ & $\mathrm{~A}_{8}$ \\
\hline & $\mathbf{A}_{10}$ & $\mathrm{~A}_{10}$ & $\mathrm{~A}_{1}$ & $\mathrm{~A}_{2}$ & $\mathrm{~A}_{3}$ & $\mathrm{~A}_{4}$ & $\mathrm{~A}_{5}$ & $\mathrm{~A}_{6}$ & $\mathrm{~A}_{7}$ & $A_{8}$ & $\mathrm{~A}_{9}$ \\
\hline
\end{tabular}
restricted as in the previous theorem 1 , and $\mathrm{E}=\{\mathrm{a}, \mathrm{b}, \mathrm{c}$, $\mathrm{d}, \mathrm{e}, \mathrm{g}, \mathrm{h}, \mathrm{i}, \mathrm{j}, \mathrm{k}$, $\mathrm{d}$ is chosen so that

$\mathrm{d}: \mathrm{E} \times \mathrm{S} \rightarrow \mathrm{S} \mathrm{d}$ chosen for this example as follows:

Table 3. The d state function selected

and selected $\mathrm{F}=\mathrm{S}$, and $\mathrm{s} 0=\mathrm{A}_{1}$.

Further decomposition can be done at will against the desired L origin meets the definition 1 of the decomposition, suppose the desired decomposition in 10 languages. Then all the pixels in the image can be clustered in 10 clusters. namely $\mathrm{L}=\mathrm{L}_{1} \oplus \mathrm{L}_{2} \oplus \mathrm{L}_{3} \oplus \ldots \oplus \mathrm{L}_{10}$, where $\mathrm{L}_{\mathrm{i}} \equiv \mathrm{M}_{\mathrm{i}}=\left\{\mathrm{S}, \mathrm{E}, \mathrm{d}, \mathrm{s} 0, \mathrm{~F}_{\mathrm{i}}\right\}$ and $\mathrm{F}_{\mathrm{i}}=\left\{\mathrm{A}_{\mathrm{i}}\right\}, \mathrm{i}=$ $1,2,3,4,5,6,7,8,9,10$.

Next create intervals (intervals making any origin must comply with the definition 4.a) as follows:

$[0,5],[6,10],[11,15],[16,20],[21,25],[26,30],[31,35]$,

$[36,40],[41,45],[46,50]$ dan $[51,255]$.

And the alphabet $\mathrm{E}=\{\mathrm{a}, \mathrm{b}, \mathrm{c}, \mathrm{d}, \mathrm{e}, \mathrm{g}, \mathrm{h}, \mathrm{i}, \mathrm{j}, \mathrm{k}\}$ and the alphabet function such that:

$\mathrm{f}[0,5]=\mathrm{a}$

$\mathrm{f}[6,10]=\mathrm{b}$

$\mathrm{f}[11,15]=\mathrm{c}$

$\mathrm{f}[21,25]=\mathrm{d}$

$\mathrm{f}[26,30]=\mathrm{e}$

$\mathrm{f}[31,35]=\mathrm{g}$

$\mathrm{f}[36,40]=\mathrm{h}$

$\mathrm{f}[41,45]=\mathrm{i}$

$\mathrm{f}[46,50]=\mathrm{j}$

$\mathrm{f}[51,255]=\mathrm{k}$

Suppose pixels g1, g2 and g3, have each neighbor based on the string value as follows:

$\mathrm{f}_{\mathrm{Np}}(\mathrm{g} 1)=$ hikedgaai

$\mathrm{f}_{\mathrm{Np}}(\mathrm{g} 2)=$ kijedkedg

$\mathrm{f}_{\mathrm{Np}}(\mathrm{g} 3)=$ edcaikaaj

Clustering results obtained using the automaton $\mathrm{M}$ as follows:

$\mathrm{g} 1 \in \mathrm{L}_{2}$

g2 $\in \mathrm{L}_{3}$

$\mathrm{g} 3 \in \mathrm{L}_{4}$

3. By using the definition 2 of the dominant language, researchers proposed the idea of clustering as follows: 
Find the dominant language of the most widely accepted of neighboring pixels $p \in G$, with the view that each pixel neighbors of $p$ produces a string by definition 4 , the function string pixels, and that two pixels are in one cluster if only if it has the same dominant language on the neighbors. This idea can be formulated in the form of researchers following definition:

\section{Definisi 6 (Similarity between pixels in a regular language):}

For example an image of $\mathrm{G}$, and $\mathrm{p} 1, \mathrm{p} 2 \in \mathrm{G}$, and $\mathrm{Np}_{1}$, $\mathrm{Np}_{2}$ respectively neigbourhood of $\mathrm{p} 1, \mathrm{p} 2$. Both are said to have a common language if and only if the dominant language on the $\mathrm{Np}_{1}$ is the same as the dominant language in $\mathrm{Np}_{2}$.

Therefore, based on the dominant language similarity, clustering in image $\mathrm{G}$ can be done.

Thus the proposed ideas.

\section{The revision version of theory}

This part is a revision of our theory about KLanguage, based on critics in reviews by reviewer.

We try to perform some another aproach to the theory so we hope the theory get precision and more powerfull.

We begun idea by construct a language band, that is a band of grayscale gradient of pixel.

Definition 7 (a language band):

A language band is a set of regular languages LB construct by a bijection function $f$ that mapping every value in grayscale gradient to a set of regular languages LB.

By this definition, we have 255 regular language, where definition 7 can be write as :

$\mathrm{LB}=\left\{\mathrm{L}_{\mathrm{i}} \mid \mathrm{L}_{\mathrm{i}}\right.$ regular language, $\left.\mathrm{i}=0,1,2, \ldots, 255\right\}$

By using theorem 1, we can costruct LB using automata DFA. Example is:

Table 4. The d state function selected

\begin{tabular}{|c|c|c|c|c|c|c|c|c|c|c|c|}
\hline \multirow{2}{*}{\multicolumn{2}{|c|}{ d }} & \multicolumn{10}{|c|}{ character input } \\
\hline & & $\mathbf{a}$ & b & c & d & $\mathbf{e}$ & $\mathrm{g}$ & h & $\mathbf{i}$ & J & $\mathbf{k}$ \\
\hline \multirow{12}{*}{$\frac{\tilde{E}}{\tilde{\omega}}$} & $\mathbf{A}_{0}$ & $\mathrm{~A}_{0}$ & $\mathrm{~A}_{2}$ & $\mathrm{~A}_{3}$ & $\mathrm{~A}_{4}$ & $\mathrm{~A}_{5}$ & $\mathrm{~A}_{6}$ & $\mathrm{~A}_{7}$ & $\mathrm{~A}_{8}$ & $\mathrm{~A}_{9}$ & $\mathrm{~A}_{10}$ \\
\hline & $\mathbf{A}_{1}$ & $\mathrm{~A}_{2}$ & $\mathrm{~A}_{3}$ & $\mathrm{~A}_{4}$ & $\mathrm{~A}_{5}$ & $\mathrm{~A}_{6}$ & $\mathrm{~A}_{7}$ & $\mathrm{~A}_{8}$ & $\mathrm{~A}_{9}$ & $\mathrm{~A}_{10}$ & $\mathrm{~A}_{0}$ \\
\hline & $\mathbf{A}_{2}$ & $\mathrm{~A}_{3}$ & $\mathrm{~A}_{4}$ & $\mathrm{~A}_{5}$ & $\mathrm{~A}_{6}$ & $\mathrm{~A}_{7}$ & $\mathrm{~A}_{8}$ & $\mathrm{~A}_{9}$ & $\mathrm{~A}_{10}$ & $\mathrm{~A}_{0}$ & $\mathrm{~A}_{2}$ \\
\hline & $\mathbf{A}_{3}$ & $\mathrm{~A}_{4}$ & $\mathrm{~A}_{5}$ & $\mathrm{~A}_{6}$ & $\mathrm{~A}_{7}$ & $\mathrm{~A}_{8}$ & $\mathrm{~A}_{9}$ & $\mathrm{~A}_{10}$ & $\mathrm{~A}_{0}$ & $\mathrm{~A}_{2}$ & $\mathrm{~A}_{3}$ \\
\hline & $\mathbf{A}_{4}$ & $\mathrm{~A}_{5}$ & $\mathrm{~A}_{6}$ & $\mathrm{~A}_{7}$ & $\mathrm{~A}_{8}$ & $\mathrm{~A}_{9}$ & $\mathrm{~A}_{10}$ & $\mathrm{~A}_{0}$ & $\mathrm{~A}_{2}$ & $\mathrm{~A}_{3}$ & $\mathrm{~A}_{4}$ \\
\hline & $\mathbf{A}_{5}$ & $\mathrm{~A}_{6}$ & $\mathrm{~A}_{7}$ & $\mathrm{~A}_{8}$ & $\mathrm{~A}_{9}$ & $\mathrm{~A}_{10}$ & $\mathrm{~A}_{0}$ & $\mathrm{~A}_{2}$ & $\mathrm{~A}_{3}$ & $\mathrm{~A}_{4}$ & $\mathrm{~A}_{5}$ \\
\hline & $\mathbf{A}_{6}$ & $\mathrm{~A}_{7}$ & $\mathrm{~A}_{8}$ & $\mathrm{~A}_{9}$ & $\mathrm{~A}_{10}$ & $\mathrm{~A}_{0}$ & $\mathrm{~A}_{2}$ & $\mathrm{~A}_{3}$ & $\mathrm{~A}_{4}$ & $\mathrm{~A}_{5}$ & $\mathrm{~A}_{6}$ \\
\hline & $\mathbf{A}_{7}$ & $\mathrm{~A}_{8}$ & $\mathrm{~A}_{9}$ & $\mathrm{~A}_{10}$ & $\mathrm{~A}_{0}$ & $\mathrm{~A}_{2}$ & $\mathrm{~A}_{3}$ & $\mathrm{~A}_{4}$ & $A_{5}$ & $\mathrm{~A}_{6}$ & $\mathrm{~A}_{7}$ \\
\hline & $\mathbf{A}_{8}$ & $\mathrm{~A}_{9}$ & $\mathrm{~A}_{10}$ & $\mathrm{~A}_{0}$ & $\mathrm{~A}_{2}$ & $\mathrm{~A}_{3}$ & $\mathrm{~A}_{4}$ & $\mathrm{~A}_{5}$ & $\mathrm{~A}_{6}$ & $\mathrm{~A}_{7}$ & $\mathrm{~A}_{8}$ \\
\hline & $\mathbf{A}_{9}$ & $\mathrm{~A}_{10}$ & $\mathrm{~A}_{0}$ & $\mathrm{~A}_{2}$ & $\mathrm{~A}_{3}$ & $\mathrm{~A}_{4}$ & $\mathrm{~A}_{5}$ & $\mathrm{~A}_{6}$ & $\mathrm{~A}_{7}$ & $\mathrm{~A}_{8}$ & $\mathrm{~A}_{9}$ \\
\hline & ... & $\ldots$ & $\ldots$ & $\ldots$ & ... & $\ldots$ & 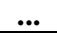 & $\ldots$ & $\cdots$ & $\ldots$ & \\
\hline & $\mathbf{A}_{255}$ & $A_{10}$ & $\mathrm{~A}_{18}$ & $\mathrm{~A}_{20}$ & $\mathrm{~A}_{30}$ & $\mathrm{~A}_{4}$ & $\mathrm{~A}_{50}$ & $\mathrm{~A}_{6}$ & $\mathrm{~A}_{7}$ & $A_{80}$ & $\mathrm{~A}_{0}$ \\
\hline
\end{tabular}

From table 4 , we get $\mathrm{L}_{\mathrm{i}} \equiv \mathrm{M}_{\mathrm{i}}=\left\{\mathrm{S}, \mathrm{E}, \mathrm{d}, \mathrm{s} 0, \mathrm{~F}_{\mathrm{i}}\right\}$, where $\mathrm{M}_{\mathrm{i}}$ is automaton, $\mathrm{F}_{\mathrm{i}}=\left\{\mathrm{A}_{\mathrm{i}}\right\}, \mathrm{i}=1,2,3, \ldots, 255$ and $\mathrm{s} 0=\mathrm{A}_{0}$.

The number of alfabet is arbitrary, where we choose the alfabet is $\{a, b, c, d, e, g, h, i, j, k\}$.

The next, we define a concept about a channel language.

Definition 8 (a channel language):

$\mathrm{L}$ is a channel language if $\mathrm{L}$ is a subset of $\mathrm{LB}$.
By definition 8,our meaning of an understanding about $\mathrm{k}$-language is $\mathrm{k}$-channel of language from a language band of grayscale. Example if we consider there are 5 region in image that we want to classified, means that there are 5 channel of language must use to classify every pixel in image.

The example for this definition:

Suppose we have channels $\mathrm{C} 1$ and $\mathrm{C} 2$, we define $\mathrm{C} 1$ and $\mathrm{C} 2$ as:

$\mathrm{C} 1=\left\{\mathrm{L}_{\mathrm{i}} \mid \mathrm{i}=2,4,6,8\right.$ and $\left.\mathrm{L}_{\mathrm{i}} \in \mathrm{LB}\right\}$

$\mathrm{C} 2=\left\{\mathrm{L}_{\mathrm{i}} \mid \mathrm{i}=1,3,5,7\right.$ and $\left.\mathrm{L}_{\mathrm{i}} \in \mathrm{LB}\right\}$

Now we can use this aproach to construct another method. The method is:

1. START

2. Define the language band:

By using theorem 1, we just build a state function that have 255 state, and some arbitrary input characters.

Construct a function like table 4.

3. Define the-k:

Example, if we have 2 region as the target of classification or clustering then we must define 2 channel of language from language band where every channel representate the one region.

If we have 2 region in image, say $\mathrm{R} 1$ and $\mathrm{R} 2$, and we build 2 channel $\mathrm{C} 1$ and $\mathrm{C} 2$ assumed representing as $\mathrm{C} 1 \equiv \mathrm{R} 1$ and $\mathrm{C} 2 \equiv \mathrm{R} 2$, and

$\mathrm{C} 1=\left\{\mathrm{L}_{\mathrm{i}} \mid \mathrm{i}=2,4,6,8\right.$ and $\left.\mathrm{L}_{\mathrm{i}} \in \mathrm{LB}\right\}$

$\mathrm{C} 2=\left\{\mathrm{L}_{\mathrm{i}} \mid \mathrm{i}=1,3,5,7\right.$ and $\left.\mathrm{L}_{\mathrm{i}} \in \mathrm{LB}\right\}$

4. Define the string representation for every pixel in 255 value variation on grayscale, by build a table that maps a string to a pixel:

Example, if we have pixel $\mathrm{P}$ have value 123 in grayscale, just choose one string from $\mathrm{L}_{123}$ from language in LB. Ofcourse there is maybe infinite string can representate $P$ from $\mathrm{L}_{123}$, but just pick up one. After that, build a table map every pixel to string representation.

Lets use table 4 as example.

We want define a string representation for pixel $\mathrm{P}$ with value is 8 in grayscale, then we get $\mathrm{L}_{8}$ as language in langugage band that reveal 8 value.

So $\mathrm{L}_{8} \equiv \mathrm{M}_{8}=\left\{\mathrm{S}, \mathrm{E}, \mathrm{d}, \mathrm{A}_{0}, \mathrm{~A}_{8}\right\}$. So we can pick up hbj as string representation of $P$.

Write $\mathrm{f}(\mathrm{P})=\mathrm{hbj}$, or $\mathrm{P} \equiv \mathrm{hbj}$.

Suppose $\mathrm{P}$ with value 8 write as $\mathrm{P}_{8}$, and $\mathrm{x}_{8}$ reveal $\mathrm{P}_{8}$ where $\mathrm{x}_{8} \in \mathrm{L}_{8}$ for all string representation, build a table:

Table 5. String representation

\begin{tabular}{|c|c|}
\hline Pixel & string representation \\
\hline $\mathrm{P}_{1}$ & $\mathrm{x} 1$ \\
\hline $\mathrm{P}_{2}$ & $\mathrm{x} 2$ \\
\hline $\mathrm{P}_{3}$ & $\mathrm{x} 3$ \\
\hline$\ldots$ & $\ldots$ \\
\hline$\ldots$ & $\ldots$ \\
\hline$\ldots$ & $\ldots$ \\
\hline $\mathrm{P}_{255}$ & $\mathrm{x} 255$ \\
\hline
\end{tabular}


5. Search the channel language for every pixel in image on N8 neigbourhood.

Example:

Say $\mathrm{P}=\mathrm{hbj}$, then the channel language of $\mathrm{P}$ is $\mathrm{C} 1$, where $\mathrm{C} 1=\left\{\mathrm{L}_{\mathrm{i}} \mid \mathrm{i}=2,4,6,8\right.$ and $\left.\mathrm{L}_{\mathrm{i}} \in \mathrm{LB}\right\}$ because $\mathrm{hbj} \in \mathrm{L}_{8}$.

6. The channel language is a dominant language of pixel.

7. Then the pixel is an element of dominant language.

8. If there is 2 or more language are the same as dominant on a pixel.

Search dominant language for N8+N16 to that pixel: Generalize it for every step in looping:

For j-loop $(\mathrm{j}=1,2,3, \ldots)$

$\mathrm{N} 8+\mathrm{N} 16+\ldots+\mathrm{NK}$.

$\mathrm{K}=\mathrm{j} .8$

Example:

Illustration for this :

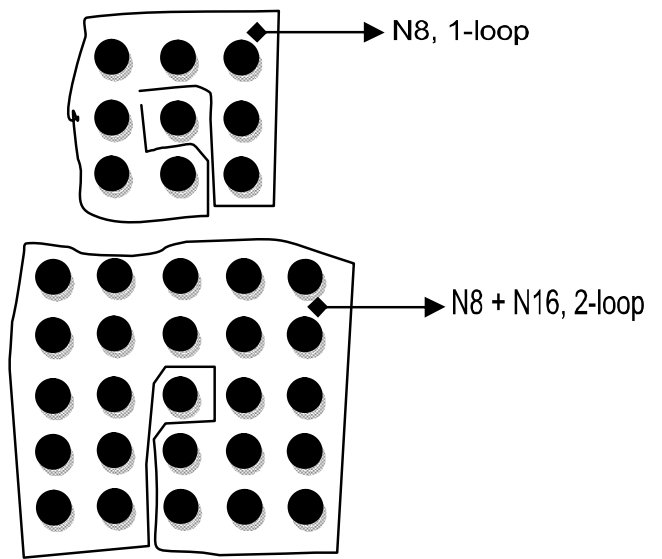

9. Back to Step 6

10. END.

Again we can construct another method, different from above. This method is:

1. START

2. Define the language band:

By using theorem 1, we just build a state function that have 255 state, and some arbitrary input characters.

3. Define the-k:

Example, if we have 5 region as the target of classification or clustering then we must define 5 channel of language from language band where every channel representate the one region.

4. Define the string representation for every pixel in 255 value variation on grayscale, by build a table that maps a string to a pixel:

Example, if we have pixel $\mathrm{P}$ have value 123 in grayscale, just choose one string from $\mathrm{L}_{123}$ from language in LB. Ofcourse there is maybe infinite string can representate $P$ from $\mathrm{L}_{123}$, but just pick up one. After that, build a table map every pixel to string representation.

5. Define $k$, how much loop we want. $i=0,1,2, \ldots$. : example we define $\mathrm{k}=4$.
6. $\mathrm{j}=1$;

7. Write $\mathrm{K}=\mathrm{j} .8$

8. Search the channel language for every pixel in image on $\mathrm{N} 8+\mathrm{N} 16+\ldots+\mathrm{NK}$ (neigbourhood of pixel):

9. $\mathrm{j}=\mathrm{j}+1$

10. if $\operatorname{not}(\mathrm{j}>\mathrm{k})$ then Back to Step 7

11. The channel language is a dominant language of pixel.

12. Then the pixel is an element of region with that dominant language.

13. END.

\section{Conclusions and recommendations}

Explanation in this paper indicate that the proposed theory researchers, could consistently perform classification at a global level of the image and also can perform up to the level of clustering pixels of the image, and all that remains consistent with the foundations being built and proposed the theory itself.

Researchers are very interested to develop this theory further proposed, based on the new questions that researchers found, that is, if the image is seen as merely a set of strings, it means that the image is no longer rooted in the quantitative significance or meaning of arithmetic, in which each pixel has a value seen Quantitative pixels (gray value), if so the meaning of the image is now rooted? Researchers noticed that the image must necessarily be rooted in semantic meanings and the meanings of logic. But what is the logic of the system that stands above the regular language? Is not our logic system is basically built on natural language (eg English) that are at the top hierarchy of language Chomsky classification.

Researchers took the decision to develop a system of regular logic-based language and hoped that the system is trying to develop a logic that researchers generally applies to all languages in the Chomsky hierarchy. Research on this has started to develop a research-based preposition calculus of regular languages, as well as researchers hope to predicate calculus, researchers tried to advance the foundations of a new logic that is different from the normal logical foundation before, and perhaps at other times researchers can propose ideas about this.

Similarly, researchers looked at the possibility of applying the ideas in this paper on the problem set of agents that communicate with each other, to see that every agent produces a set of strings that can be accepted by another agent. In this case, researchers have also started trying to develop the assumption that an agent is an automaton.

This paper was written thus may be useful. We are sorry if there are typos in the writing symbols.

\section{References}

[1] Alwi, Aslan and Muslim, Munira, "Generalization Edge Detection Operators and Laplace Operator in any dimension and any resolution image", Prosiding konferensi internasional ICCSE UGM 2012.

[2] Ahmad, Usman., "Pengolahan Citra Digital \& Teknik Pemrogramannya". ISBN 979-756-072-6. 2005, pp. 111-224. 
[3] Grassmann, Winfried Karl and Tremblay Jean-Paul., "Logic and Discrete Mathematics, a computer science prespective" 1996, Prentice-Hall Inc. USA.

[4] Putra, Darma., "Pengolahan Citra Digital". ISBN 978-979-291443-6, 2010, pp. 248-249

[5] Utdirartatmo, Firrar "Teori Bahasa dan Otomata" 2005, Penerbit Graha Ilmu, Yogyakarta. 